\title{
VIBRATIONAL CHARACTERISTICS OF A ROTATING SHAFT CONTAINING A TRANSVERSE CRACK
}

\author{
Dr. SABAH MOHAMMED JAMEL \\ PROFESSOR
}

\author{
ZIAD SHAKEEB AL-SARRAF MOHAMMED NAJEEB AL-RAWI \\ ASSISTANT LEACTURE \\ ASSISTANT LEACTURE \\ Mechanical Engineering Department, College of Engineering, Mosul University
}

\section{ABSTRACT:}

The influence of a transverse crack upon the dynamic behavior of a rotating shaft is studied. Introduction of such a crack results in lower transverse natural frequencies due to the added local flexibility. The strain energy release function is related to the compliance of the cracked shaft that is to the local flexibility due to introduction of crack. This function is related to the stress intensity factor, which for transverse of a shaft with a crack has a known expression. As a result, the local flexibility of the shaft due to the presence of the crack has been computed. This result, can be further utilized to yield the dynamic response of a shaft with complex geometry. Starting from the equation of motion for the shaft under bending to derive the expression of calculating the natural frequency of the shaft.

Two cases of fixing the shaft are suggested in this study to investigate and analyze the vibration characteristics of the shaft with and without cracks. The fundamental natural frequency showed strong dependence on the crack depth, This dependence is smaller as the order of the frequency increase. Experimental results are in close agreement with those practical from the theoretical analysis. Finally, the results showed that the change in dynamic response due to the crack is high enough to allow the detection of the crack and estimation of its magnitude.

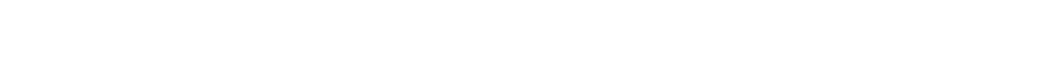

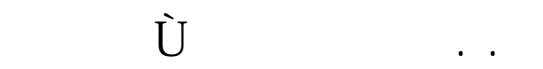

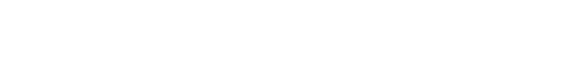 \\ Eŷ̀ứ ù ũté

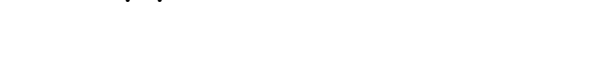 \\ tŷrúc ū ũté
}

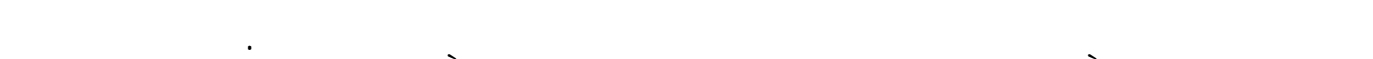

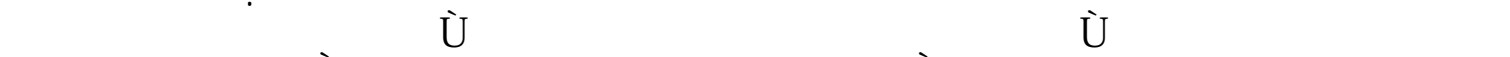

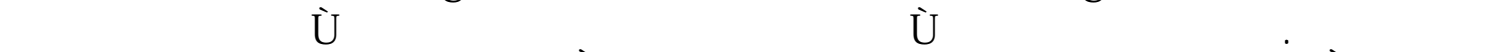

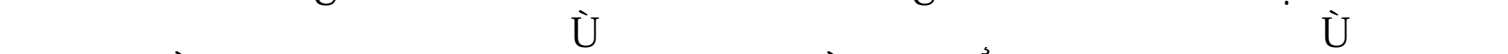

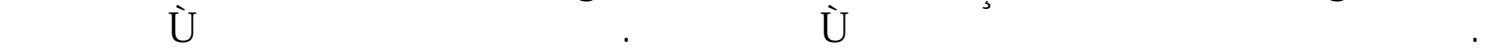

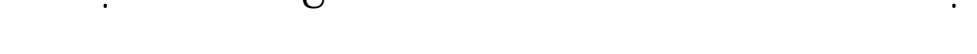

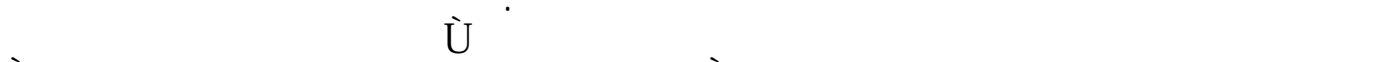

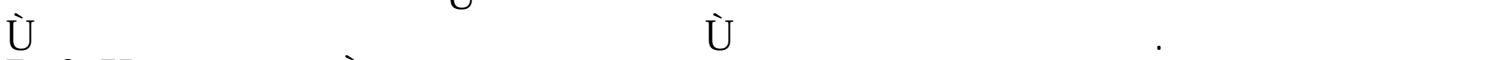

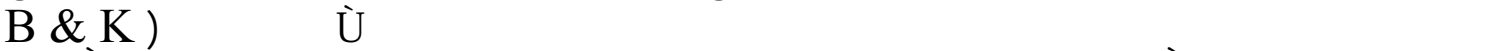

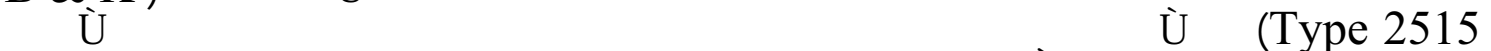

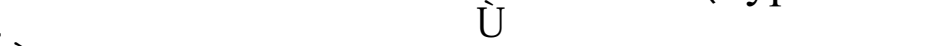
ũ bứḱŕçB 


\section{NOMENCLATURE:}

$\begin{array}{ll}\text { A } & \text { Cross-section area of the shaft }\left(\mathrm{m}^{2}\right) \\ \mathrm{a} & \text { Crack depth }(\mathrm{mm}) \\ \mathrm{C} & \text { Local flexibility }(\text { Compliance) }(\mathrm{m} / \mathrm{N}) \\ \mathrm{C}_{1}, \mathrm{C}_{2}, \mathrm{C}_{3}, \mathrm{C}_{4} & \text { Constant } \\ \mathrm{C}_{\mathrm{w}} & \text { Wave velocity }(\mathrm{m} / \mathrm{sec}) \\ \mathrm{D} & \text { Diameter of the shaft }(\mathrm{mm}) \\ \mathrm{E} & \text { Young modulus of elasticity }\left(\mathrm{N} / \mathrm{m}^{2}\right) \\ \mathrm{I} & \text { Second moment of area }\left(\mathrm{m}^{4}\right) \\ \mathrm{K}_{\mathrm{III}} & \text { Stress intensity factor } \\ \mathrm{L} & \text { Length of the shaft }(\mathrm{m}) \\ \mathrm{M} & \text { Bending moment }(\mathrm{N} . \mathrm{m}) \\ \mathrm{P}(\mathrm{x}) & \text { Uniform load }(\mathrm{N}) \\ \mathrm{R} & \text { Radius of the shaft }(\mathrm{mm}) \\ \mathrm{r} & \text { Distance to the crack } \\ \mathrm{T} & \text { Torque }(\mathrm{N} . \mathrm{m}) \\ \mathrm{V} & \text { Shear force }(\mathrm{N}) \\ v & \text { Poisson's ratio } \\ \mathrm{X} & \text { Displacement }(\mathrm{mm}) \\ \mathrm{Y} & \text { Deflection }(\mathrm{mm})\end{array}$

Greek

$\begin{array}{ll}\beta_{n} & \text { Frequency factor } \\ \rho & \text { Density }\left(\mathrm{kg} / \mathrm{m}^{3}\right) \\ \omega & \text { Frequency with crack }\left(\mathrm{H}_{\mathrm{Z}}\right) \\ \omega_{\mathrm{o}} & \text { Frequency without crack }\left(\mathrm{H}_{\mathrm{Z}}\right) \\ \omega_{n} & \text { Natural Frequency }\left(\mathrm{H}_{\mathrm{Z}}\right)\end{array}$

\section{INTRODUCTION}

Since the mid-seventies the dynamic behavior of cracked shaft has been investigated increasingly because damages in turbines, generators, pumps, and other machines occurred quite often. This caused costly shutdowns of entire plants and was sometimes followed by the total loss of the machine. Fracture of a shaft which means crack are originated at points of stress concentration either inherent in design or introduced during fabricate on or operation.

Cracks defined as micro or macro interrupt the continuums are in principle unavoidable. Also the initiation occurs during the vibration especially when the shaft is unbalance or mis-align [1].

Singularity in elastic structure can introduce their dynamic behavior. Jones and O'Donnnell [2] showed that axisymmetric solids have considerable local flexibility at their junctures. Cracks are associated with local flexibilities that can introduce considerable local flexibilities, which influence considerably the dynamic response of 
the structure. Such analyses have been reported for turbine vanes [3], welded plates [4] and for framed structures [5]. It was shown experimentally that changes in natural frequencies due to cracks can be safely detected in certain machines and structures and their magnitude can be estimated. Cracks often appear in a variety of machinery.

\section{LOCAL FLEXIBILITY}

Sih and Loeber [6,7] studied the somewhat similar problem of transverse wave scattering about a penny-shaped crack. They studied the scattering of a given wave due to the penny-shaped crack by way of the field equation solved by a finite Hankel transform. Although the same procedure could be used for problem at hand, and the energy method was utilized, based on the wealth of data existing for the strain energy release function. Also by using the vibration analyzer devise to calculate the frequency of the shaft then to make a relation between the change in frequency with the compliance.

A transverse crack of depth (a) is considered on a shaft of radius (R). The shaft has local flexibility due to crack; it's depending on the direction of the applied forces.

We considered just only bending deformation, and the axial force which give coupling with transverse motion of the cracked shaft will not considered here, also shear stress are not considered. Therefor the shaft is bent by a pure bending moment.

The strain energy in the shaft due to a torque $\mathrm{T}$ is

$$
U=\frac{T^{2} C}{2}
$$

where $\mathrm{C}$ is the local flexibility (compliance) of the shaft due to crack.

$$
G=\frac{\partial U}{\partial A}=\frac{1}{2} T^{2} \frac{\partial C}{\partial a} \frac{1}{2(\pi R-a)}
$$

Hertzberg [8] suggested that by measuring the flexibility of a test specimen or a component model, with various crack depth (a), the value of the gradient $\frac{\partial C}{\partial a}$ as function of (a) could be determined, leading to the determination of the strain energy release function. Miller [9] demonstrated that the energy release rate $\mathrm{G}$ could be related to the stress intensity factor $\mathrm{K}$ as

$$
G=\frac{K_{I I I}^{2}}{2 \mu}
$$

Where $\mu$ is the shear modulus and the mode III stress intensity factor $K_{I I I}$ is defined by the relation 
$(\tau)=\frac{K_{I I I}}{\sqrt{2 \pi r}}\left[\sin \frac{\theta}{2}\right]++$ terms of order $r^{0}$

Giving the shear stresses in the vicinity of the crack at distance (R) from its tip. Equation (2) and (3) yield

$$
\frac{d C}{d a}=\frac{K_{I I I}^{2}}{T^{2} \mu} 2(\pi R-a)
$$

Integrating

$$
C=\int_{0}^{a} \frac{K_{I I I}^{2}}{T^{2} \mu} 2(\pi R-a) d a
$$

An expression is needed for the stress intensity factor $K_{I I I}$ for the problem at hand. For a shaft with a crack Bueckner [10] has outlined a method for the determination of $\mathrm{K}$ as a function of the crack depth. Benthem and Koiter [11] have approximated the stress intensity factor $\mathrm{K}$ for a solid cylinder with a crack through the following expression: -

$$
K=\frac{3}{8}\left[1+\frac{1}{2} \lambda^{2}+\frac{3}{8} \lambda^{2}+\frac{5}{16} \lambda^{3}+\frac{35}{128} \lambda^{4}+\frac{1}{2} \lambda^{2} 0.208 \lambda^{5}\right]
$$

where $\lambda=(\mathrm{R}-\mathrm{a}) / \mathrm{R}$, Fig. 1 .

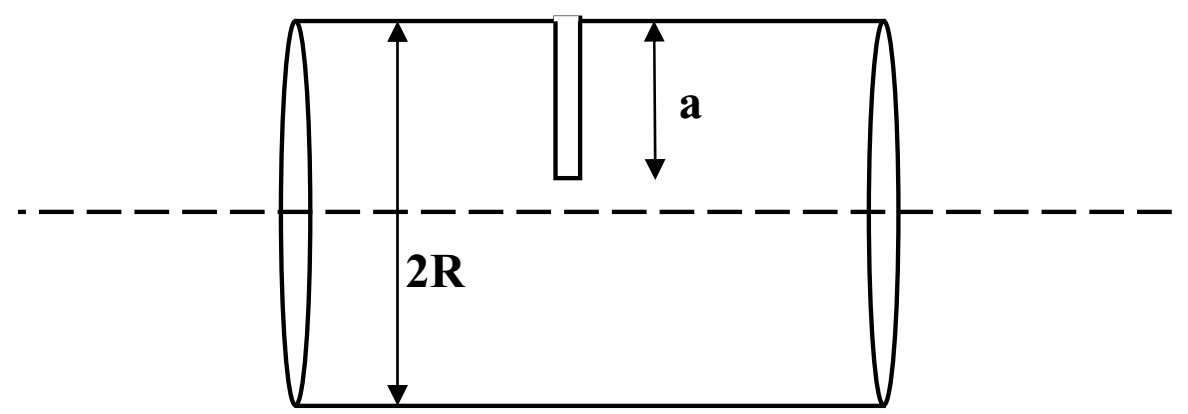

Fig 1. Geometry of a shaft with a transverse crack

The dimensionless stress intensity factor $\mathrm{K}$ is defined by the relation

$$
\tau=K \frac{2 T}{\pi(R-a)^{3}}\left[\frac{a(R-a)}{R}\right]^{1 / 2} \frac{1}{\sqrt{2 r}}
$$

Therefore, comparison with equation (4) yields 


$$
K_{I I I}=\frac{2 T}{(R-a)^{3}}\left[\frac{a(R-a)}{\pi R}\right]^{1 / 2} K
$$

The flexibility ( C ) in dimensionless form becomes

$$
\frac{\pi R^{3} \mu}{4} C=\frac{1}{R} \int_{0}^{a} \frac{a}{R} \frac{2(\pi R-a)}{R} \frac{R^{5}}{(R-a)^{3}} K^{2}(a) d a
$$

The integral has the value

$$
\begin{aligned}
C= & 0.035(1-a / R)^{-4}+0.01(1-a / R)+0.029(1-a / R)^{2}+ \\
& +0.0086(1-a / R)^{3}+0.0044(1-a / R)^{4}+0.0025(1-a / R)^{6} \\
& +0.0017(1-a / R)^{7}+0.008(1-a / R)^{9}-0.092
\end{aligned}
$$

\section{EQUATION OF MOTION}

In order to find the special function of the natural frequency of the shaft it should be calculate the equation of motion that representing the analysis of the shaft under the shear and bending effects, then to find the deflection of the shaft. A horizontal shaft is used with a length (L), and a uniform distributed load $\mathrm{P}(\mathrm{x})$ on the whole shaft. This accomplished by take a segment from the shaft in order to study the force effect. Fig. 2.

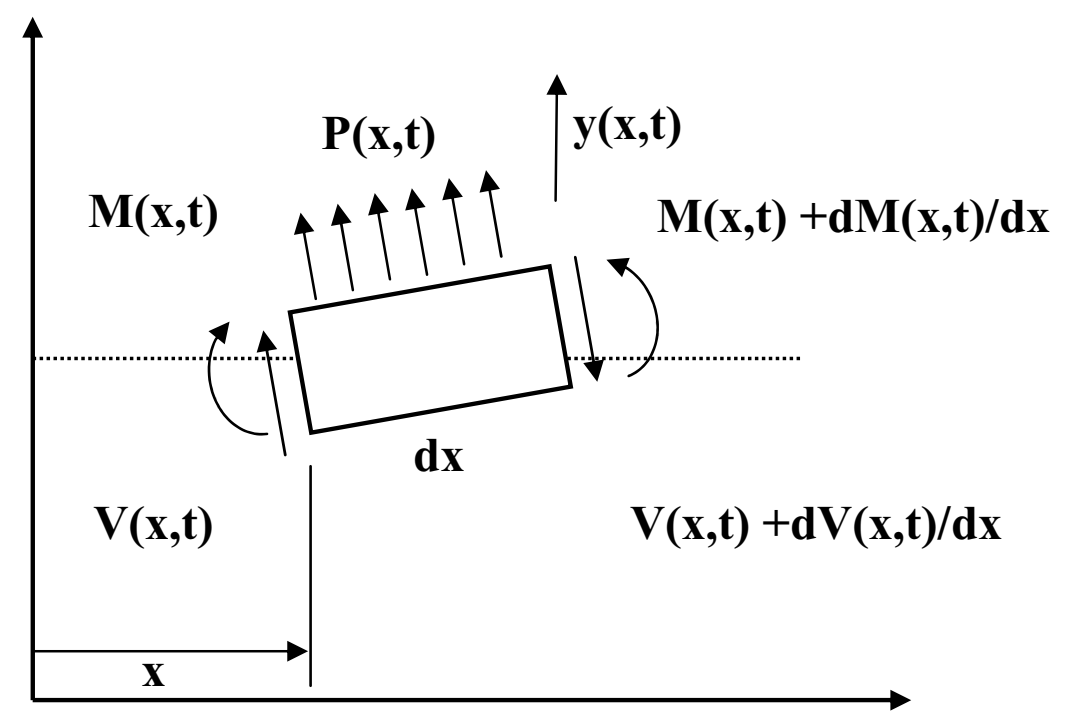

Fig 2. Effect of Forces on the rotating shaft

We assume that the bending moment of the shaft is $M(x, t)$ and the shear force is $\mathrm{V}(\mathrm{x}, \mathrm{t})$, then the segment have a displacement $(\mathrm{x})$ from the left end and have a length $(\mathrm{dx})$. By taking the summation of the forces in the vertical direction equal to zero.

$V+P d x-(V+d V)=0$ 
And the summation of the moments applied on the shaft equal to zero.

$$
M-(M+d M)+V d x=0
$$

From the equation (11) and (12), we get

$$
P(x, t)=\frac{\partial^{2} M(x, t)}{\partial x^{2}}
$$

From the strength of materials [12], the following relation ship is derived between the elastic curve (curvature) and bending moment, and also bending stiffness (EI) of the shaft as below.

$$
\frac{1}{R}=\frac{M}{E I}
$$

After applying the equation above we get the function of fourth order as,

$$
P(x, t)=E I \frac{\partial^{4} y(x, t)}{\partial x^{4}}
$$

Depending on the Newton's second law the equation (15) written as

$$
P(x, t)=\rho A(x) d x \frac{\partial^{2} y(x, t)}{\partial t^{2}}
$$

where $\rho=$ density of the shaft metal

Applying Equation (16) and (15) in equation (13), get

$$
E I(x) \frac{\partial^{4} y(x, t)}{\partial x^{4}}=P(x, t)-\rho A(x) d x \frac{\partial^{2} y(x, t)}{\partial t^{2}}
$$

For the case of the free vibration, $P(x, t)=0$. Then equation $(17)$ may be written as

$$
\begin{aligned}
& C_{w}{ }^{2} \frac{\partial^{4} y(x, t)}{\partial x^{4}}+\frac{\partial^{2} y(x, t)}{\partial t^{2}}=0 \\
& C_{w}=\sqrt{\frac{E I}{\rho A}} \\
& \text { where } C_{w}=\text { Wave velocity }
\end{aligned}
$$




\section{Initial conditions}

Since, equation (18) involves a second order derivative to time and a fourth order derivative with respect to $(\mathrm{x})$, two initial conditions and four boundary conditions are needed for finding a solution. This is accomplished by using the separation of variables technique.

Let a function $\mathrm{y}(\mathrm{x}, \mathrm{t})$ be the product of two separate functions, one with respect to $(\mathrm{x})$ and the another with respect to $(\mathrm{t})$.

$$
y(x, t)=\phi_{n}(x) \cdot g_{n}(t)
$$

now,

$$
\begin{aligned}
& \frac{\partial^{2} y}{\partial t^{2}}=\frac{\partial^{2} g_{n}(t)}{\partial t^{2}} \cdot \phi_{n}(x) \\
& \frac{\partial^{4} y}{\partial x^{4}}=\frac{\partial^{4} \phi_{n}(x)}{\partial x^{4}} \cdot g_{n}(t)
\end{aligned}
$$

Substitution in equation (18), to get

$$
\begin{aligned}
& C_{w}{ }^{2} \frac{\partial^{4} \phi_{n}(x)}{\partial x^{4}} \cdot g_{n}(t)+\frac{\partial^{2} g_{n}(t)}{\partial t^{2}} \cdot \phi_{n}(x)=0 \\
& \frac{C_{w}^{2}}{\phi_{n}(x)} \frac{\partial^{4} \phi_{n}(x)}{\partial x^{4}}=\frac{1}{g_{n}(t)} \frac{\partial^{2} g_{n}(t)}{\partial t^{2}}=-\omega_{n}^{2} \\
& \frac{\partial^{4} \phi_{n}(x)}{\partial x^{4}}-\beta_{n}^{4} \phi_{n}(x)=0
\end{aligned}
$$

where, $\beta_{n}{ }^{4}=\frac{\omega_{n}{ }^{2}}{C_{w}{ }^{2}}$

then the general solution become

$$
y(x, t)=C_{1} \cos \beta x+C_{2} \sin \beta x+C_{3} \cosh \beta x+C_{4} \sinh \beta x
$$

where $\mathrm{C}_{1}, \mathrm{C}_{2}, \mathrm{C}_{3}, \mathrm{C}_{4}$ constants, and the natural frequency is given by:- 
$\omega_{n}=\beta_{n L}^{2} \sqrt{\frac{E I}{\rho A L^{4}}}$

\section{THEORETICAL AND EXPERIMENTAL INVESTIGATION}

The research contributes a study on a model of two cases of fixing end condition of rotating shaft to analysis the vibration behavior and effect on the dynamic characteristics with and without a crack, and also to find the change of local flexibility (compliance).

\section{The First Case:}

(Fixed simply supported shaft)

The shaft is fixed to the left end and the other end is simply supported Fig. 3. The shaft used in this study, had a diameter $(\mathrm{D}=8 \mathrm{~mm})$, and a length is $(\mathrm{L}=0.6 \mathrm{~m})$, density $\left(\rho=7800 \mathrm{~K}_{\mathrm{g}} / \mathrm{m}^{3}\right)$, the Young modulus $\left(\mathrm{E}=207 * 10^{9} \mathrm{~N} / \mathrm{m}^{2}\right)$, second moment of area $\left(\mathrm{I}=\pi^{*} \mathrm{D}^{4} / 64 \mathrm{~m}^{4}\right)$, and Frequency factor $\left(\beta_{n L 1}=3.926602\right)[3]$.

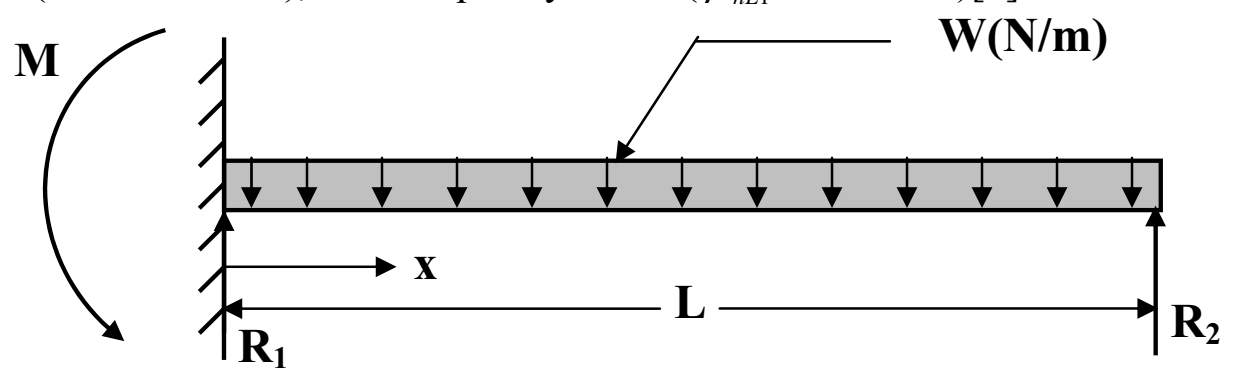

Fig 3. Model of the first state of fixing the shaft

First the value of the natural frequency of the shaft from equation (27) was calculated, In case of no crack. Then the calculation repeated experimentally to find the natural frequency of the rotating shaft, by means of vibration analyzer (B \& K Type $2515)$ to investigate the vibration characteristics of shaft.

Second, it is used equation (10) to find the local flexibility of the shaft and change this property by increasing the depth of crack, and effect this on the vibration response of the shaft. Then in order to find the values of frequency due to crack theoretically, we can put the values get from equation (10) in the relation between the local flexibility (C) and change in natural frequency with and without a crack [13]. 
$C=\frac{L}{D}\left[\frac{1}{\left(\frac{\omega}{\omega_{o}}\right)^{2}}-1\right]$

Experimental model Fig. 4 is accomplished where a D.C Motor through coupling connects the shaft to the left is made for this purpose, and pinned to the right end by use bracket. The speed of shaft must be controlled by using voltage variable transformer (shown below) how give the range between (0-250) volts. The calculation of frequency was taken using a portable vibration analyzer (B \& K Type 2515) to investigate the vibration spectrum of rotating shaft with and without crack. The vibration signal was received from the accelerometer that put contact to the near point of the rotating shaft (the accelerometer was fixed on the bearing of shaft). Then transform to the vibration analyzer to analysis by using (F.F.T.) relation, and the output shown by the digital monitor screen of the vibration device.

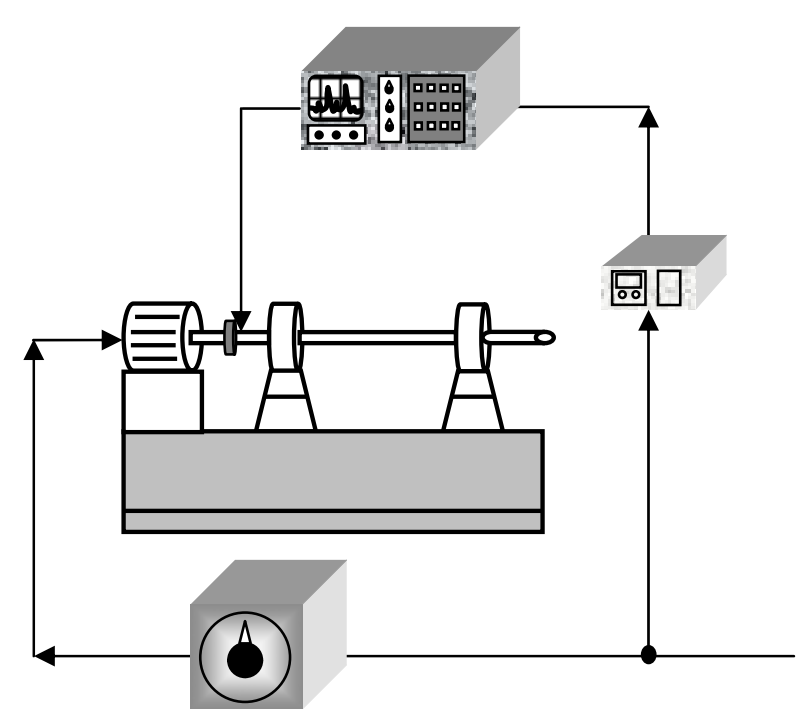

Fig 4.Experimental model of the shaft

The experimental result is plotted in Fig. 5.Vs the theoretical function. In the experiment, shafts were firstly examined by calculating the natural frequency and investigate the vibration dynamic behavior. After that the crack was made by means of saw-cut which is supported transversely to the center of the shaft, also the depth of crack in this study is taken between $(\mathrm{a} / \mathrm{D}=0-0.75)$. 


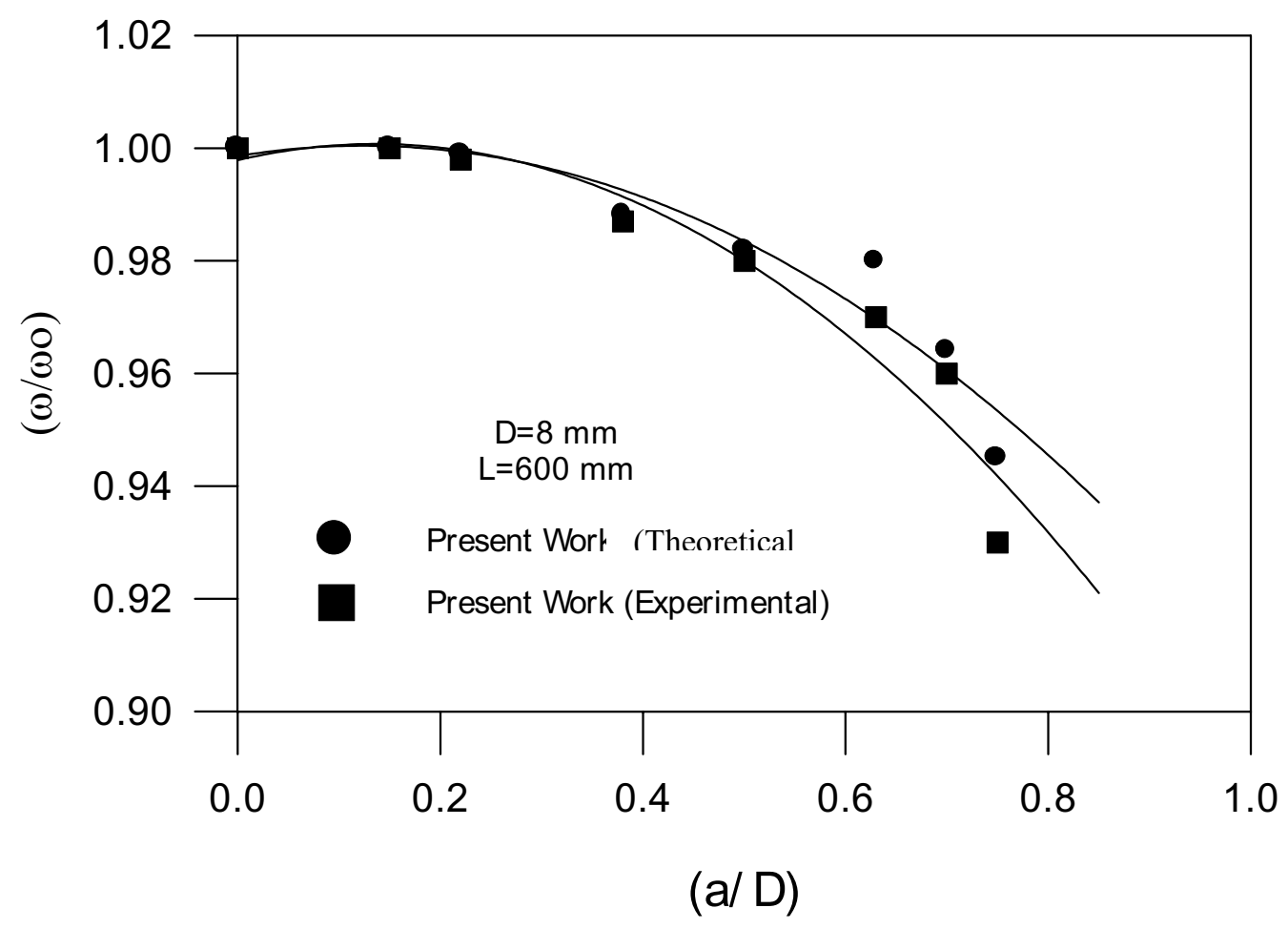

Fig 5.Frequency drop vs crack depth ratio

Due to figure above the measured value of the frequency change $\omega / \omega_{o}$ against the relative crack depth is done, here $\omega$ is the transverse natural frequency with the crack and $\omega_{o}$ the same frequency without the crack. There will be some deference between the theoretical and experimental results of change of natural frequency with crack depth ratio.

So this is normally because due to experimental part there is some parameter effect to the frequency like the effect of rotation speed of the shaft, the accuracy of crack depth. Also in case of low lubrication of the shaft and bearings then the friction occurred and causes change in frequency values, in spite of the fixing of accelerometer to the near point of the rotating shaft. All these points will causes some difference between the theoretical and experimental results, but on the other side the experimental results are in close agreement with the theoretical.

\section{The Second Case:}

(Fixed simply supported shaft with a concentrated load at the center)

The shaft is fixed to the left end and the other end is simply supported to the right but with concentrated load (rotor disk) at the center Fig. 6. The shaft was used in this study, with diameter $(\mathrm{D}=8 \mathrm{~mm})$, and a length is $(\mathrm{L}=0.6,0.5,0.4 \mathrm{~m})$, density $(\rho=7800$ $\left.\mathrm{K}_{\mathrm{g}} / \mathrm{m}^{3}\right)$, the Young modulus $\left(\mathrm{E}=207 * 10^{9} \mathrm{~N} / \mathrm{m}^{2}\right)$. The disk have a mass $(\mathrm{m}=0.139 \mathrm{Kg})$ and the density of disk $\left(\rho=2770 \mathrm{~K}_{\mathrm{g}} / \mathrm{m}^{3}\right)$, the second moment of area $\left(\mathrm{I}=\pi^{*} \mathrm{D}^{4} / 64 \mathrm{~m}^{4}\right)$, Frequency factor $\left(\beta_{n L 1}=3.926602\right)$. 


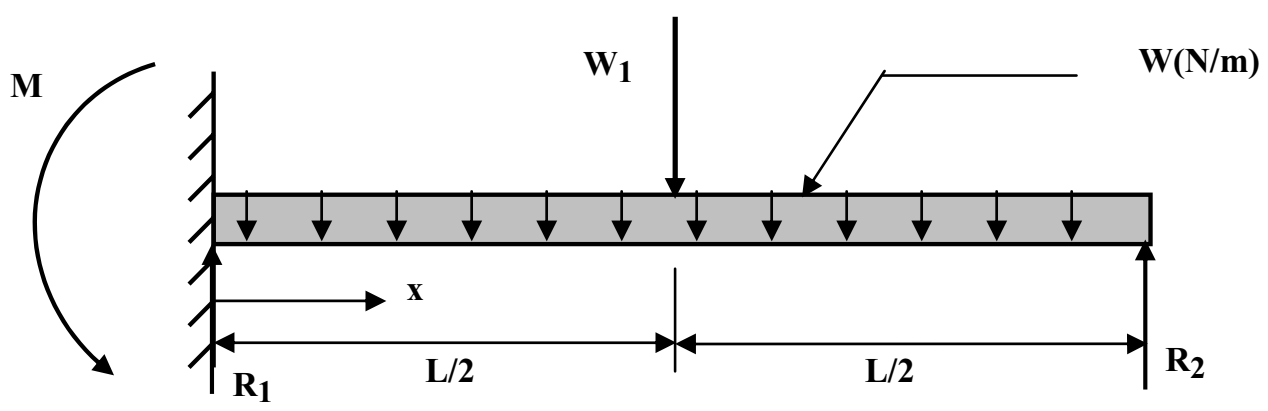

Fig 6. Model of the second state of fixing the shaft

As in the first case, we calculate the value of the natural frequency of the shaft in case of no crack and no concentrated load; this is accomplished by using equations mentioned before. Then we repeat it after fixing the disk in the middle of shaft length, then make a crack near the disk position and calculate the change of frequency due to variable crack depth Fig. 7 . Using three lengths of shaft $(0.6,0.5,0.4 \mathrm{~m})$ does this and the mass of disk is $(0.139 \mathrm{Kg})$.

Second we calculate experimentally the value of the natural frequency of the shaft and change this value in case of no crack, no load (disk) and with disk and crack for three length of shaft as in Fig. 8.The theoretical and experimental results of figures $(7,8)$ below show a good close in values, and there will be some difference because due to experimental part of the effect of rotation speed of the shaft, and the accuracy of crack depth. Also the fixed of the accelerometer to the near point of the rotating shaft. All will exhibit some change in values in comparison with theoretical results.

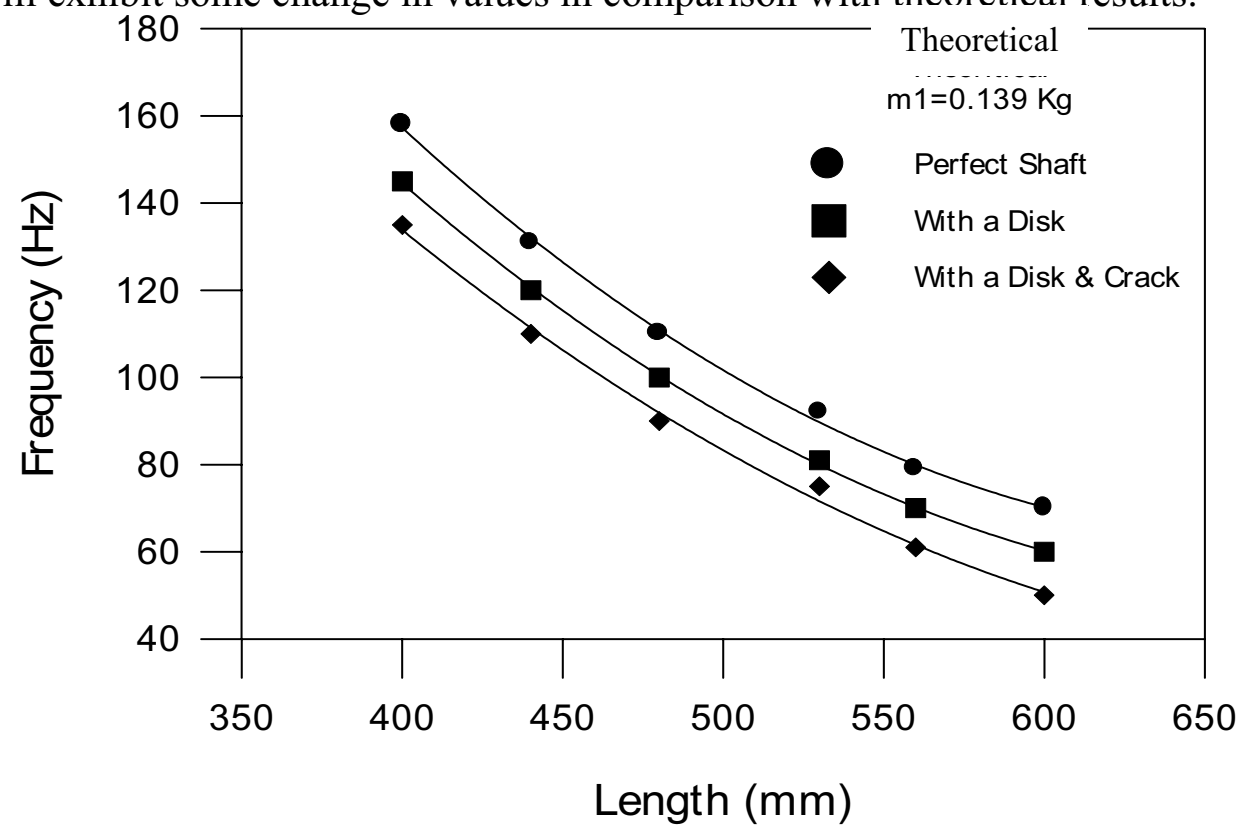

Fig 7.Effect the crack and the load (disk)

On the change of frequency (Theoretical) 


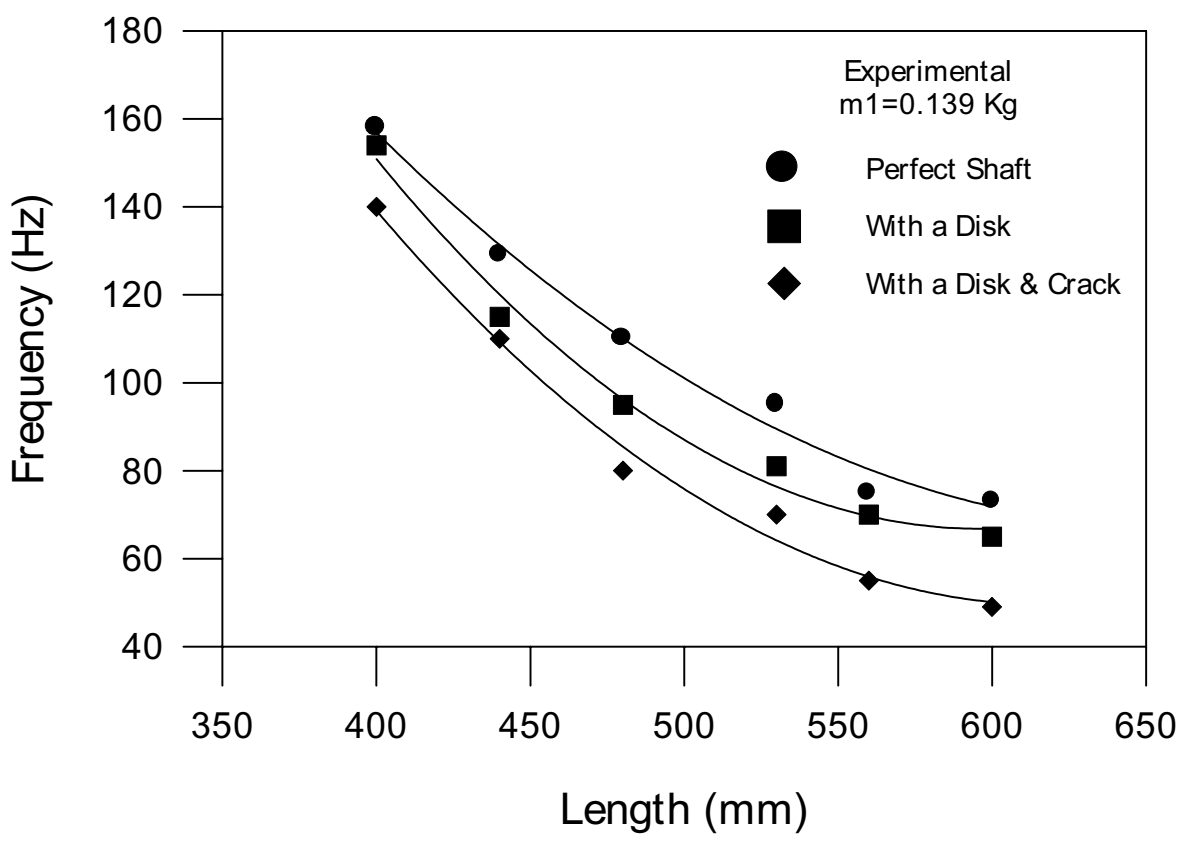

Fig 8. Effect the crack and the load (disk)

On the change of frequency (Experimental)

\section{THE COMPLIANCE (LOCAL FLEXIBILITY)}

To find the local flexibility of the rotating shaft theoretically, we used equation (10) to find the local flexibility of the shaft and note this change of property by increasing the depth of crack and effect this on the vibration response of the shaft.

In this work it suggest the range of crack depth between $(0-0.75 \mathrm{a} / \mathrm{D})$ then put these values in equation (10) was derived before, in order to find the change of flexibility due to increasing crack. In experiment we used the relation between the local flexibility (C) and change in natural frequency with and without a crack [13]. Fig. 9.

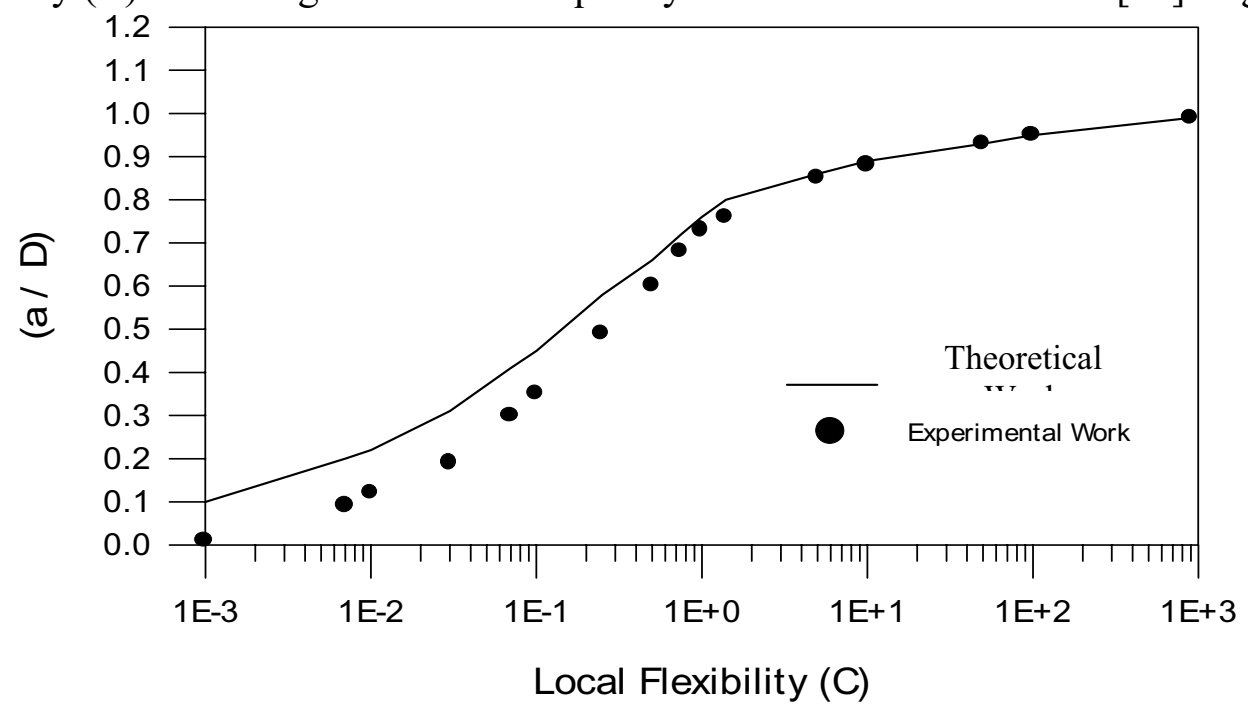

Fig 9. Theoretical against Experimental results for

The dimensionless crack depth against local flexibility 
From the results of change of frequency and equation (10) the cracked shaft local flexibility (compliance) was computed and entered in figure above, as a function of the crack depth. At small crack depths (a/D) there is a considerable discrepancy between theoretical and experimental results which was to be expected due to the difficulty in accurate measurement of small frequency differences which appear for cracks with $(\mathrm{a} / \mathrm{D})$ in the range $(0-0.4)$.

The dimensionless Local flexibility functions, equation (10) are plotted In Fig. 10. As in figure below,

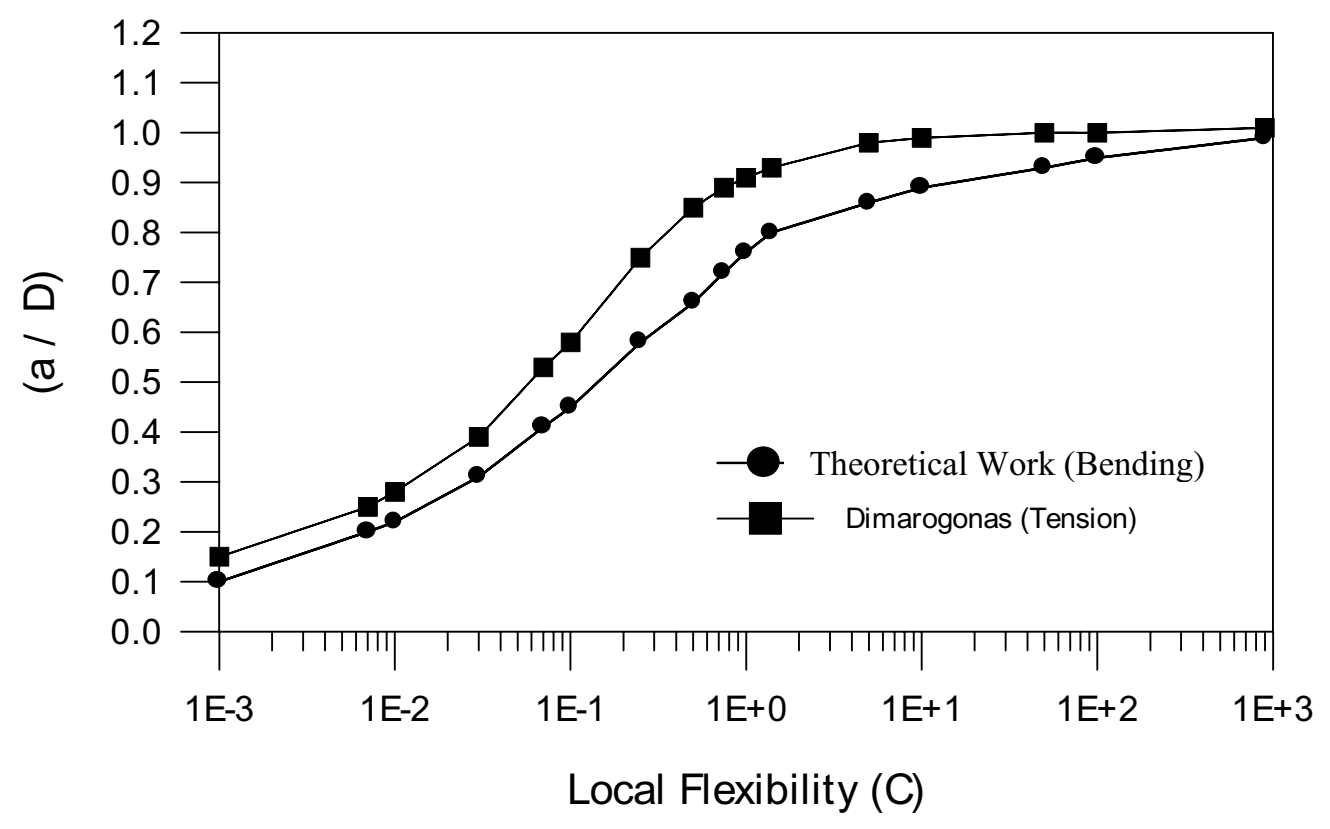

Fig 10. Dimensionless Flexibility of the Cracked Shaft In Bending, and In Tension

They observed the difference between the values of flexibility that calculated from the equation (10) theoretically and compare it by the values contributed by Dimarogonas [13] who study the compliance of the stationary cracked shaft with open crack.

The results showed the variable in points were gets from analytical solution because in this study the shaft was under bending only and other property was neglected .So these assumptions will leads to some difference between the two studies, but they have the same behavior in changing the local flexibility due to the crack depth ratio.

\section{DISCUSSION}

The natural frequency of a rotating shaft found to be considerably influenced by the presence of a transverse crack. The quantitative evaluation of this effect based on the derivation of an equation of motion to derive the formula of calculating the natural frequency of the rotating shaft. Also it is depending on the strain energy function to get the integral relation between the local flexibility and the stress intensity factor.

By the present method, it is notice from the curves mentioned above that the natural frequency of the rotating shaft will be decreased by increasing the depth of crack 
refer to the changing of the vibration spectrum of the shaft Fig (11). Also increasing the crack depth rapidly decreases the values of frequencies. This is done by using a portable vibration analyzer (B \& K Type 2515) with magnetic acceleration which support to the near point of rotating shaft

It is noticed that the vibration characteristic of the rotating shaft changes due to the crack depth, which causes reduction in natural frequencies. Also this lower of frequency will increase by increasing the crack depth so it's used the ratio of the crack to the diameter of the shaft in the range $(0-0.75)$.

The effect of adding the mass on the shaft (rotor disk) causes to decrease the values of natural frequencies, And by increasing the crack depth on the shaft which lead to lowered in natural frequencies due to supporting the disk. As mentioned above.

The crack on the rotating shaft will change in some property like the local flexibility. So the local flexibility of a shaft in bending due to the crack is evaluated from the theoretical and experimental results relating to the derivation of the strain energy release function to the crack depth, contributed by some authors.

These methods can have many practical applications because there is a wealth of analytical results for strain energy release function. For present work it's noticed that local flexibility increased by increasing the crack depth and this observed by calculating the theoretical values of local flexibility from the equation derived above. And for the experimental results the calculate the values of natural frequencies of the rotating shaft with and without crack then used the expression which depend on finding the flexibility from the change of frequencies to get the local flexibility.

It is noticed that through the crack detectability. Cracks of smaller than 0.2 relative crack depth can be identified only in a quite environment by a skilled observer. For such depths above 0.2 the identification is very easy.

For industrial application this level of crack detectability is rather adequate for most application. Moreover, careful measurement and good knowledge of the uncracked shaft behavior might render the method applicable even for relative crack depths of the order of 0.1 .

Finally, this work will represent a technique for non-destructive testing methods depending on, use the vibration analysis and the spectrum of vibration and monitoring it on a screen. So it can used also for identification of the location and the magnitude of the crack on a rotating shaft, without direct inspection, even at running conditions. It allows also for continuous monitoring in shaft in service, especially for machine which has welded rotors and frequent inspections are impractical. 


\section{REFERENCES}

[1] Donald, J. and Wulpi, "Failures of Shafts", Metallurgical Consultant, 2000.

[2] Jones, D. P. and O'Donnel, W.J. "Local flexibility for axisymmetric junctures". Trans ASME J. Engng Ind. 1-5 (1971).

[3] Rao, S.S., "Mechanical Vibration", $3{ }^{\text {rd }}$ edition, 1995.

[4] Chondros, T. G. and Dimarogonas, A. D. "Identification of cracks in welded joints of complex structures", J. Sound and Vibration 69, pp. 531-538. 1980.

[5] Chondros, T. G. and Dimarogonas, A. D. "Identification of cracks in circular plates welded at the contour", ASME J. paper No.79-DET-106. Design Engng Tech, Conf., St. Louis, and U.S.A. (Sept. 1980).

[6] Sih, G. C. and Loeber, J. E. "Vibration of an Elastic Solid Containing a PennyShaped Crack". J. Acoust. Soc. Am.44, pp. 1237-1245 (1968).

[7] Loeber, J. F. and Sih, G. C. "wave Scattering about a Penny-Shaped Crack on a Bimaterial Interface, in Dynamic Crack Propagation”. (Ed. G. Sih), pp. 513-528, Nordhoff, Leyden (1973).

[8] Richard. W. Hertzberg. "Deformation and Fracture Mechanics of Engineering Materials". $4^{\text {th }}$ edition. John Wiley \& Sons, Inc. (1996).

[9] Miller, K. J., "An Introduction to Fracture Mechanics", Mechanical and Thermal behavior of Metallic Materials, pp. 97-131, (1982).

[10] Bueckner, H. F. "Field Singularities and related integral representations". In Methods of Analysis and Solution of Crack Problems, (Ed. G. Sih), pp. 239. Noordhoff, Leyden. (1973).

[11] Benthem, J. P. and Koiter, W. T. "Asymptotic approximations to crack problems". ibid, pp. 174-198. (1981).

[12] Morrow, H. W., "Static and Strength of Materials", $3^{\text {rd }}$ edition, Prentice Hall, (1998).

[13] Dimarogonas, A., and Massouros, G., "Torsional Vibration of a Shaft with a Circumferential Crack", Engineering Fracture Mechanics, Vol. 15, No.34, pp. 439-444, (1981). 

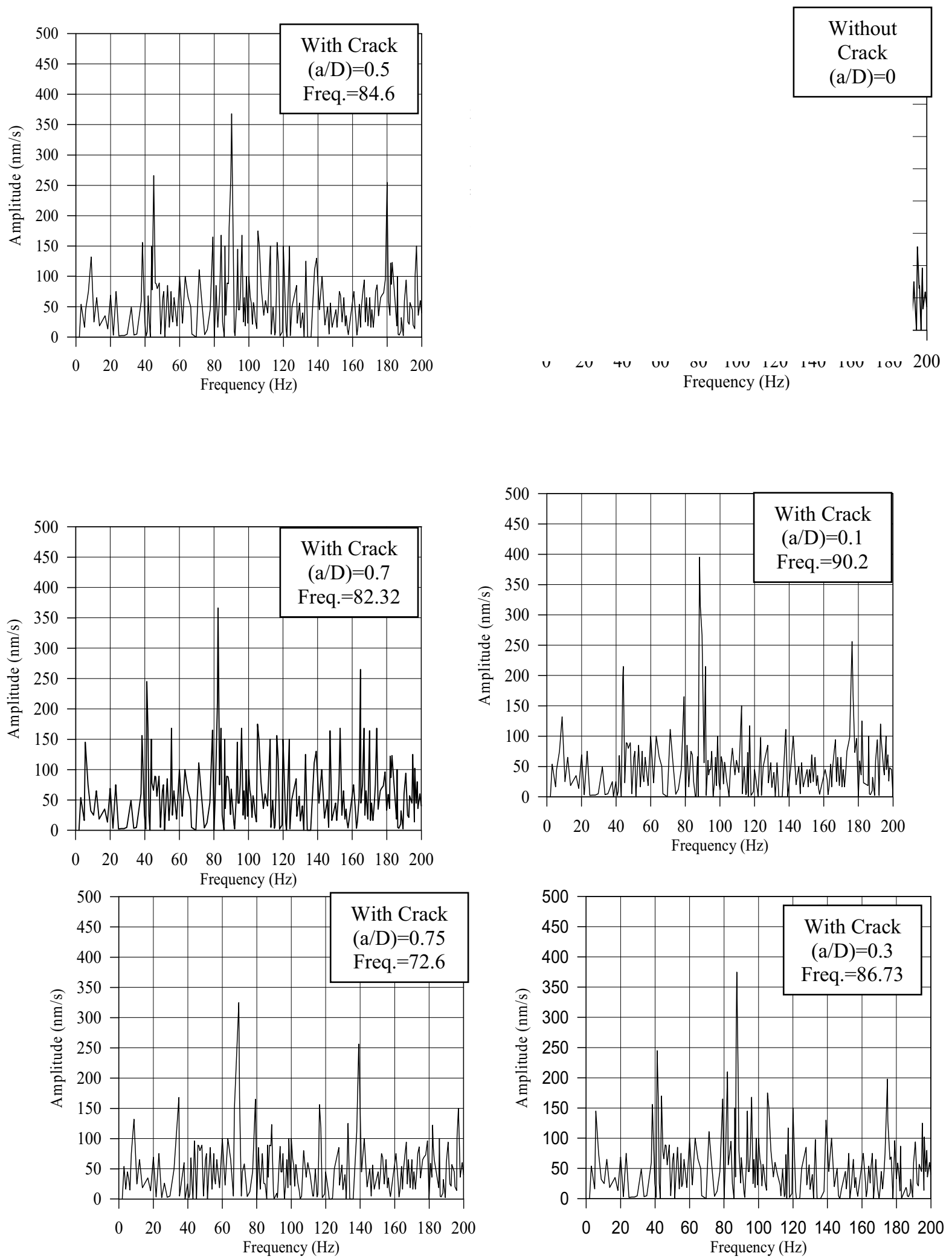

Fig 11. Experimental measurement of spectrum vibration

for several crack depth of shaft 